\title{
Apresentação: Estudos de Gramática Formal
}

\author{
Gabriel de Ávila Othero \\ Universidade Federal do Rio Grande do Sul, Porto Alegre, Rio Grande do Sul / Brasil \\ gabriel.othero@ufrgs.br \\ Sonia Maria Lazzarini Cyrino \\ Universidade Estadual de Campinas, Campinas, São Paulo / Brasil \\ cyrino@unicamp.br
}

Esta edição da Revista de Estudos da Linguagem se dedica ao tema "Estudos de Gramática Formal". A ideia para organizarmos este número temático da RELIN surgiu a partir de um convite da editorachefe, a Heliana Mello (UFMG), a quem devemos deixar registrado nosso agradecimento pela imensa ajuda na organização desta edição.

Os estudos linguísticos formais têm longa tradição no Brasil, em especial as áreas de Fonologia e Morfologia (cf. CÂMARA JR., 1969 e 1970, por exemplo), com outras áreas (como a Sintaxe e a Semântica) se fortalecendo especialmente com a chegada de textos gerativistas ao país ao longo das décadas de 1970 e 1980. Contudo, nos parece que os estudos em gramática formal vêm perdendo seu espaço no cenário nacional nos últimos anos. ${ }^{1}$ Por isso, uma edição dedicada aos estudos linguísticos formais nos pareceu oportuno. Vislumbramos uma edição que contemplasse as "áreas centrais" da gramática: Fonologia, Morfologia, Sintaxe, Semântica e Pragmática. E, de fato, recebemos artigos que

\footnotetext{
${ }^{1}$ A reedição recente de obras clássicas de gramática formal (como a tradução comentada de Estruturas sintáticas e a edição crítica de Estrutura da Língua Portuguesa), no entanto, mostra que os estudos gramaticais de cunho formal seguem despertando interesse (cf. CHOMSKY, 2015, e CÂMARA JR., 2019, nas referências).
} 
tratavam de assuntos relacionados a todas essas áreas - ou que faziam interface entre duas ou mais áreas.

Após longo processo de revisão anônima por pares e de editoração e diálogo com os autores, o resultado que agora sai publicado aqui é uma edição sobre gramática formal que apresenta 19 artigos, resultados da pesquisa de 25 diferentes pesquisadores, de 18 instituições de ensino brasileiras (PUCRS, UFBA, UFF, UFMG, UFPR, UFRGS, UFRJ, UFRPE, UFS, UFSC, UFSCar, UFV, UnB, Unicamp, Unifesp, Unipampa, USP, UTFPR).

Os artigos estão organizados em ordem alfabética, mas podem ser acessados em qualquer ordem - uma das vantagens da plataforma eletrônica das revistas atuais. O primeiro texto é A extração de genitivos e a periferia esquerda do sintagma de determinante do português brasileiro, de Adeilson P. Sedrins (UFRPE), que apresenta um estudo que "busca ampliar para o PB [português brasileiro] a validação da postulação da projeção de uma categoria funcional $\mathrm{F}$, como a projeção mais proeminente na estrutura nominal localizada acima de DP" em construções genitivas. Sua pesquisa adota a perspectiva da sintaxe cartográfica (cf. CINQUE, 1999; BELLETI, 2004; RIZZI, 2004) e traz dados de diferentes línguas (como inglês, espanhol, holandês) para sustentar sua análise para o PB.

$\mathrm{O}$ próximo artigo é A intensificação de adjetivos: fatores contextuais, de Luisandro Mendes de Souza (UFRGS), em que o autor "discute a intensificação de adjetivos graduais modificados por muito a partir de uma abordagem referencial do significado", dando ênfase na análise de "anomalias semânticas na combinação de muito com adjetivos absolutos de grau máximo". Sua proposta é que uma expressão do tipo muito + adjetivo pressuponha "que todos os indivíduos a quem a predicação se aplica sejam A, e que a identificação de um grau máximo como uma função total dos absolutos de grau máximo [tenha] características de uma implicatura”, em uma clara interface entre semântica e pragmática.

Depois desse artigo, continuamos na área da Pragmática (dessa vez, com uma interface com a Sintaxe), com o texto A pragmaticalização de capaz em português brasileiro e a codificação da atitude do falante, de Patrícia Rodrigues (UFPR) e Marcus V. Lunguinho (UnB). Nesse trabalho, os autores examinam "as propriedades das construções do português brasileiro com a expressão capaz, como Capaz que a Maria 
viajou", que podem assumir diferentes significados, a depender de seu padrão entoacional: "[c]om uma entoação plana, capaz é interpretado como um modal epistêmico, enquanto com a acentuação em capaz (...), essa expressão passa a ser interpretada como um marcador pragmático, expressando surpresa ou o ponto de vista contrário do falante". Sua hipótese é de que cada interpretação está associada a uma estrutura sintática diferente, tornando o estudo interessante tanto do ponto de vista pragmático como sintático.

Na sequência, Ohana T. B. Severo (UFRJ), apresenta o artigo An experimental study on the interpretation of bare singulars in Mexican Spanish, em que trata da interpretação de nominais singulares nus no espanhol mexicano. O texto tem viés experimental e apresenta os resultados de um teste com 134 informantes, em um experimento de compreensão off-line, em que os informantes escolhiam entre interpretações de volume ou de número, a partir de diferentes cenários. A conclusão resultante do experimento foi que "a ausência de morfema de plural (sintaxe massiva) não desencadeia uma interpretação massiva de singulares nus; singulares nus são interpretados como nomes contáveis pluralizados mesmo que eles não estejam pluralizados”.

$\mathrm{O}$ artigo seguinte, Adjetivos em PB: posição pré-nominal e modificação de evento, de Thais Deschamps (UFPR), trata da relação entre a posição pré-nominal dos adjetivos do português brasileiro e as propriedades dos adjetivos avaliativos em línguas como o inglês e o espanhol. A autora considera que os adjetivos avaliativos podem selecionar um argumento evento, e busca traçar "um paralelo entre essa propriedade e a posição pré-nominal em PB de maneira mais ampla".

Em seguida, temos o artigo de Antonio José Maria Codina Bobia (UFV), Bare singular count nouns in Dutch as a heritage language in Brazil, sendo, neste número temático, um outro trabalho que aborda os nominais nus do português brasileiro. O autor avalia "a distribuição de DPs em sentenças genéricas em falantes de neerlandês como língua de herança em Holambra, Brasil, especialmente em relação à aceitabilidade de nomes singulares nus". Também em um estudo experimental, o autor tenta averiguar se, "devido à influência do $\mathrm{PB}$ os falantes de Holambra poderiam aceitar NNs [nominais nus] em contextos semelhantes aos dos brasileiros", uma vez que a distribuição de nominais singulares nus é mais restrita na L1 desses falantes. Os resultados do estudo sugerem que "uma gramática ligeiramente diferente surgiu nos falantes de holandês de 
Holambra, sofrendo atrito devido à influência do PB", especificamente no caso de construções com singulares nus.

$\mathrm{Na}$ sequência, temos o artigo Capaz como marcador negativo enfático no dialeto gaúcho, de Rerisson Cavalcante (UFBA) e Leonor Simioni (Unipampa), outro texto em que a partícula "capaz" é investigada, dessa vez na interface entre sintaxe, semântica e pragmática. Os autores comparam o uso de capaz com outros marcadores negativos do português e propõem a estrutura sintática de construções com a partícula.

No artigo Coordenação e paralelismo, Ana Márcia Martins da Silva (PUCRS) se debruça sobre estruturas coordenadas encontradas em textos reais de disciplinas de produção textual de graduandos, com o objetivo de "chegar a um princípio de paralelismo que seja eficiente para a identificação de estruturas malformadas".

Em seguida, temos o trabalho de Aquiles Tescari Neto (Unicamp), que trata Da posição do verbo temático em cinco variedades ibéricas, que investiga o movimento de verbo em duas línguas: o português (brasileiro e moçambicano) e o espanhol (colombiano, venezuelano e peruano). Através de resultados de julgamento de gramaticalidade, o autor analisa quatro padrões de ordenação da forma verbal em relação a um advérbio e o seu objeto. $O$ autor constatou que há variação intralinguística e interlinguística, e seus resultados favorecem "um abandono do movimento nuclear (para a sintaxe da subida do verbo), em proveito tão somente da assunção de movimentos sintagmáticos."

O próximo texto, Deslocamento de tópico contrastivo no português brasileiro: uma proposta semântico-pragmática, de Fernanda Rosa Silva (UFF), também está situado na interface semântica-pragmática. A autora investiga propriedades informacionais de construções com tópico contrastivo em $\mathrm{PB}$, dando ênfase a estes quatro pontos: (i) posição de origem do elemento deslocado; (ii) tipo de pergunta (aberta ou fechada) no contexto discursivo; (iii) elemento com ou sem retomada pronominal; e (iv) tipo de relação contrastiva. A autora chega à conclusão que "a marcação prosódica do tópico contrastivo indica contraste", ao passo que "o deslocamento [de um constituinte] tem a função de direcionar a atenção do ouvinte para um elemento disponível no contexto" e depois "atribuir uma propriedade a esse elemento".

No texto Fonologia autônoma, sintaxe mais simples: explorando as interfaces na Arquitetura em Paralelo, Giuseppe Varaschin (UFSC) explora a interface Fonologia-Sintaxe, no modelo 
da sintaxe mais simples (cf. CULICOVER; JACKENDOFF, 2005; JACKENDOFF, 2007). O autor argumenta em favor da visão de Culicover e Jackendoff (2005) discutindo a regra do acento nuclear (CHOMSKY; HALLE, 1968; HALLE; VERGNAUD, 1987) e chegando à conclusão de que é possível atribuir mais autonomia entre os diferentes componentes gramaticais, em especial à fonologia e à prosódia (com relação à sintaxe).

$\mathrm{O}$ próximo artigo, $\mathrm{O}$ constituinte-QU in situ e os efeitos de Common Ground no português brasileiro infantil, de Clariana Lara Vieira (USP) e Elaine B. Grolla (USP), traz um estudo sobre o efeito pragmático de perguntas com elemento-QU in situ em PB em fase de aquisição da linguagem. As autoras investigam os efeitos de Common Ground e chegam à conclusão de que existe "uma associação entre o QU-in situ e o contexto pragmático, tanto nos dados adultos (...) quanto nos dados infantis".

No trabalho $O$ modelo do Léxico-Gramática no Brasil, de Roana Rodrigues (UFS/UFSCar) e Larissa Picoli (UFSCar), encontramos uma apresentação do modelo do Léxico-Gramática, tendo por base trabalhos realizados no Brasil desde o ano 2000. As autoras fizeram uma detalhada revisão da literatura nacional dentro do modelo: "[c]ompilamos e descrevemos 38 trabalhos, entre teses, dissertações e artigos, sob o arcabouço do LG no Brasil", apresentando os avanços de pesquisas na área em solo nacional.

$\mathrm{Na}$ sequência, temos outro artigo que trabalha com dados de aquisição da linguagem: $O$ papel da sintaxe na aquisição de adjetivos no Português Brasileiro, de Cristina de Souza Prim (UTFPR). A autora analisa o processo de aquisição de adjetivos qualificativos em $\mathrm{PB}$, a partir de um ponto de vista sintático. Seu objetivo central é revelar como a criança "aprende" a posição do adjetivo com relação ao nome que modifica durante o processo de aquisição. Ela argumenta que o PB é "uma língua de traços fortes opcionais, que se aplicam para adjetivos, mas também para WHs e para possessivos".

O próximo texto, Os verbos ir, dever e poder e seus infinitivos: sintaxe interna e externa, de Mauricio S. Resende (Unicamp) e Paulo Ângelo de Araújo-Adriano (Unicamp), “investiga as propriedades sintáticas internas (isto é, a constituição morfofonológica) e externas (ou seja, a relação com outros constituintes da sentença) dos infinitivos que ocorrem com os verbos ir, dever e poder". Os autores comparam duas 
análises de construções com esses verbos, uma no quadro da Morfologia Distribuída e outra análise de cunho minimalista.

$\mathrm{O}$ artigo Prefix allomorphy in complex verbs of Brazilian Portuguese, de Indaiá Bassani (Unifesp), também investiga propriedades morfológicas de verbos, dessa vez, verbos de mudança morfologicamente complexos. O objetivo central do texto é verificar "se há ou não correlações entre a forma morfofonológica do prefixo, a semântica da raiz e a estrutura argumental do verbo". A autora conclui que "não é possível associar exclusivamente as formas morfológicas prefixais à semântica específica da raiz ou ao comportamento morfossintático do verbo, embora seja possível observar tendências gerais" e que a "teoria de alomorfia proposta em Embick (2010), baseada em localidade e linearidade, se mostra efetiva para analisar a escolha dos alomorfes dos núcleos R (relacionador), v e Th (Vogal temática)”.

$\mathrm{Na}$ sequência, temos o trabalho de Thayse Letícia Ferreira (UFSCar), Sobre o licenciamento de "sequer" em interrogativas do PB, em que a autora investiga a distribuição e as restrições que atuam sobre o item lexical "sequer" em contexto de interrogação em PB. Ela chega à conclusão de que as "interrogativas polares, de alternativa e de constituinte $(w h)$ são ambientes propícios para o aparecimento de 'sequer', ao passo que questões de alternativa polar (A-não-A) bloqueiam sistematicamente a presença desse item".

Luiz Fernando Ferreira (USP) e Ana Müller (USP) são os coautores do próximo artigo, The relevance of future vs. non-future languages for the understanding of the role of tense in counterfactuals sentences. Em diversas línguas pertencentes a diferentes famílias, sentenças contrafactuais, ou seja, aquelas cuja proposição denotada é falsa, exibem morfologia de passado. Para discutir as propostas teóricas sobre contrafactualidade, os autores deste artigo examinam as sentenças contrafactuais em karitiana, uma língua que tem um sistema temporal futuro vs. não-futuro. O estudo é relevante pois busca aprofundar a descrição das sentenças contrafactuais nessa língua que é tipologicamente distinta das línguas tratadas na literatura em relação à expressão da contrafactualidade. Esses dados, segundo os autores, "desafiam o poder explanatório das principais abordagens teóricas e apoiam uma delas", fato que mostra a contribuição de um estudo dessa natureza.

Finalmente, no artigo Verbos de movimento do português brasileiro: evidências contra uma tipologia binária, Letícia L. 
Meirelles (UFMG) analisa o comportamento sintático de verbos de movimento do PB, "com o intuito de mostrar que o português brasileiro não se caracteriza como uma língua emoldurada nos verbos (verb-framed language)". Para ela, "a presença de sintagmas preposicionados, de adjuntos adverbiais e de orações subordinadas, determinam como nossa língua expressa as propriedades semânticas trajetória, direção e maneira em sentenças com verbos de movimento", o que torna difícil classificar o PB dentro de um padrão tipológico restrito, no que toca a tipologia verbal, tal como proposto por Talmy $(1985,2000)$.

Esperamos que este volume dedicado a recentes estudos linguísticos formais no Brasil possa cumprir seu objetivo de preencher uma necessidade no contexto da pesquisa universitária, ao fazer circular hipóteses, resultados e análises decorrentes de diversas questões levantadas nas investigações das áreas nucleares da gramática.

\section{Referências}

BELLETTI, A. (Ed.). Structures and beyond: the cartography of syntactic structures. New York: Oxford University Press, 2004.

CÂMARA JR., J. M. Problemas de linguística descritiva. Petrópolis: Vozes, 1969.

CÂMARA JR., J. M. Estrutura da língua portuguesa. Petrópolis: Vozes, 1970.

CÂMARA JR., J. M. Estrutura da língua portuguesa: edição crítica. Edição, estabelecimento de texto, introdução e notas de Emilio G. Pagotto, Maria Cristina Figueiredo Silva e Manoel Mourivaldo SantiagoAlmeida. Petrópolis: Vozes, 2019.

CHOMSKY, N. Estruturas sintáticas: tradução comentada. Tradução e comentários de Gabriel de Ávila Othero e Sergio Menuzzi. Petrópolis: Vozes, 2015.

CHOMSKY, N.; HALLE, M. The sound pattern of English. New York: Harper \& Row, 1968.

CINQUE, G. Adverbs and Functional Heads. A Cross-linguistic Perspective. New York: Oxford University Press, 1999. 
CULICOVER, P.; JACKENDOFF. R. Simpler syntax. Oxford: Oxford University Press, 2005. DOI: https://doi.org/10.1093/acprof:o so/9780199271092.001.0001

EMBICK, D. Localism versus Globalism in Morphology and Phonology. Cambridge: MIT Press, 2010. doi: https://doi.org/10.7551/ mitpress/9780262014229.001.0001

JACKENDOFF, R. Language, consciousness, culture: essays on mental structure. Cambridge: MIT Press, 2007. DOI: https://doi.org/10.7551/ mitpress/4111.001.0001

HALLE, M.; VERGNAUD, J-R. An Essay on Stress. Cambridge: MIT Press, 1987.

RIZZI, L. The structure of CP and IP. The Cartography of Syntactic Structures. New York: Oxford University Press, 2004. v. 2.

TALMY, L. Lexicalization Patterns: Semantic Structure in Lexical Forms. In: SHOPEN, T. (Ed.). Language Typology and Syntactic Description: Grammatical Categories and the Lexicon. New York: Cambridge University Press, 1985. v. 3, p. 57-149.

TALMY, L. Toward a Cognitive Semantics: Typology and Process in Concept Structuring. Cambridge, MA: MIT Press, 2000. 